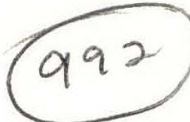

\title{
NEUTRON CAPTURE IN REACTOR STRUCTURAL MATERIALS
}

\author{
R. L. Macklin
}

\section{OAK RIDGE NATIONAL LABORATORY}




\section{DISCLAIMER}

This report was prepared as an account of work sponsored by an agency of the United States Government. Neither the United States Government nor any agency Thereof, nor any of their employees, makes any warranty, express or implied, or assumes any legal liability or responsibility for the accuracy, completeness, or usefulness of any information, apparatus, product, or process disclosed, or represents that its use would not infringe privately owned rights. Reference herein to any specific commercial product, process, or service by trade name, trademark, manufacturer, or otherwise does not necessarily constitute or imply its endorsement, recommendation, or favoring by the United States Government or any agency thereof. The views and opinions of authors expressed herein do not necessarily state or reflect those of the United States Government or any agency thereof. 


\section{DISCLAIMER}

Portions of this document may be illegible in electronic image products. Images are produced from the best available original document. 
This report was prepared as an account of work sponsored by the United States Government. Neither the United States nor the United States Atomic Energy Commission, nor any of their employees, nor any of their contractors, subcontractors, or their employees, makes any warranty, express or implied, or assumes any legal liability or responsibility for the accuracy, completeness or usefulness of any information, apparatus, product or process disclosed, or represents that its use would not infringe privately owned rights. 
Contract No. W-7405-eng-26

PHYSICS DIVISION

NEUTRON CAPTURE IN REACTOR STRUCTURAL MATERIALS

R. L. Macklin

FEBRUARY 1973

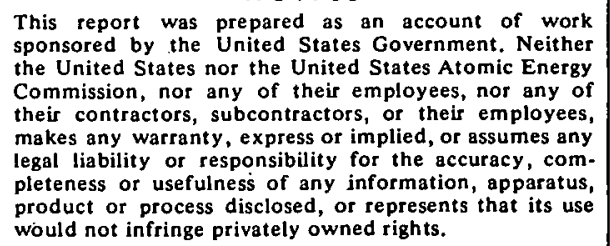

product or process disclosed, or represents
would not infringe privately owned rights.

NOTICE This document contains information of a preliminary nature and was prepared primarily for internal use at the Oak Ridge National Laboratory. It is subject to revision or corruction and therefore does not represent a final report.

OAK RIDGE NATIONAL LABORATORY
Oak Ridge, Tennessee 37830
operated by
UNION CARBIDE CORPORATION
for the
U.S. ATOMIC ENERGY COMMISSTON 


\section{ABSTRACT}

A brief review is given of the capture and transmission programs at ORELA listing resident and visiting personnel and nuclides being emphasized in early 1973. Comments on capture cross section analysis and data reduction and a critical survey of capture detectors are included. 
NEUTRON CAPTURE IN REACTOR STRUCTURAL MATERIALS

An EACRP-EANDC meeting on the above topic, stressing $\mathrm{Ni}, \mathrm{Fe}$ and $\mathrm{Cr}$, is scheduled for May 8-9, 1973, at Karlsruhe. Written comments and contributions under various topics have been solicited.

I. At the Oak Ridge Electron Linear Accelerator (ORELA) there are indeed capture and transmission measurements under way. Time-of-flight transmission work at 18 , 50, 80 and 200 meters is carried on by J. A. Harvey, N. W. Hill, W. M. Good, C. H. Johnson, J. L. Fowler, F. G. Perey, T. A. Love, W. E. Kinney, and visiting scientists from Idaho Falls, Savannah River, Brookhaven, Taiwan, and various US universities. The last group also includes undergraduate.students on summer assignments and. in alternating work-study programs. Transmission measurements on 160 , ${ }^{23} \mathrm{Na},{ }^{27} \mathrm{Al},{ }^{6} \mathrm{Li}$, stables isotopes of calcium, silicon, sulfur, titanium, zirconium,

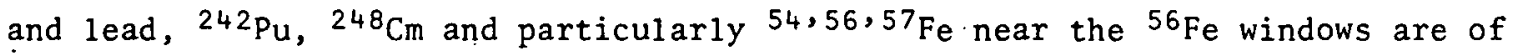
current interest.

Capture cross section measurements on ${ }^{238} \mathrm{U}$ and $235 \mathrm{U}$ have been made by G. de Saussure, R. W. Ingle, E. G. Silver, and R. B. Perez at 40 meters with a large liquid scintillation tank. An extensive program on enriched stable isotope capture is also being conducted (R. L. Macklin and J. Halperin) using small nonhydrogenous liquid scintillators and on-line pulse height. weighting to give a response like an ideal Moxon-Rae detector. ${ }^{1)}$ Resonance capture in silicon (reported at the Asilomar Conference on Photonuclear Reactions), ${ }^{9} \mathrm{Nb},{ }^{59} \mathrm{Co},{ }^{103} \mathrm{Rh}$, ${ }^{139} \mathrm{La},{ }^{45} \mathrm{Sc}$ and $\mathrm{p}$-wave capture in ${ }^{56} \mathrm{Fe}$ above $100 \mathrm{keV}$ are of current interest. Measurements on capture by ${ }^{92} \mathrm{Mo},{ }^{111} \mathrm{Cd},{ }^{19} \mathrm{~F},{ }^{27} \mathrm{~A} 1,{ }^{205} \mathrm{Tl}$, and stable isotopes of $\mathrm{Sr}$, $\mathrm{Zr}, \mathrm{Ca}, \mathrm{Cr}^{2)}, \mathrm{Ti}, \mathrm{Te}, \mathrm{Ba}$, and $\mathrm{Pb}$ are in various stages of analysis. Most of the work on resonance capture analysis and publication must be done in collaboration with visiting scientists from other laboratories and universities (B. J. Allen and co-workers at Lucas Heights, AAEC, G. Vanpraet (Belgium), E. D. Earle (Chalk 
River, Canada), O. A. Wasson (Brookhaven National Laboratory), and R. R. Winters (Denison University, Ohio).

II. Background, Resolution, Corrections, Normalization and Analysis

We enjoy a very clean pulsed beam at ORELA both in terms of sharp collimation and off-energy neutron contamination. Neutrons whose energy does not correspond to flight time directly from the moderator are under $1 \%$ of the direct beam up to at least $1 \mathrm{MeV} .{ }^{3}$ )

The sharp definition of the beam has permitted our capture detectors to be placed close to the sample position with only an allowance of a few millimeters for penumbra, alignment and vacuum window. ${ }^{4)}$ While a uranium target would provide a few times more neutron intensity than our present tantalum target ${ }^{3)}$ it would also introduce a sample dependent background from delayed fission neutrons.

Corrections of a few percent are made to the gamma energy yield data (deadtime, room background, sample scattered neutron background and particularly resonance self-protection). As the enriched samples are rare and expensive we try to use just one sample thickness in the general case. This leads to substantial (up to a factor of 2 or so) resonance self-protection corrections at the lower end of our energy range $(2.5 \mathrm{keV})$ and sparse statistics up near $1 \mathrm{MeV}$. As several other laboratories are well equipped to measure capture up to several $\mathrm{keV}$, we have generally avoided taking data below $2.5 \mathrm{keV}$.

Our present choice of flux standardization is based on the saturated resonance technique $\left(4.9 \mathrm{eV} \mathrm{Au}, 0.005 \mathrm{~cm}\right.$ thickness) and the thin ${ }^{6} \mathrm{Li}$ glass scintillation monitor. ${ }^{5)}$ The first seems clearly preferable to thermal cross section normalization as one relies on the literature only for the $2 \%$ or so (backscatter) correction rather than the entire standard thermal cross section. By use of a re-entrant or cup shaped sample the backscatter correction could be reduced still further if desirable. (Of course, it is nice to check the thermal value against the saturated resonance capture, but the experimental setup may need to be 
substantially modified to deal carefully with the thermal energy range.) The present accuracy of the ${ }^{6} \mathrm{Li}(n, \alpha)$ cross section at and above the $0.25 \mathrm{MeV}$ resonance is not entirely satisfactory. Experiments currently underway, particularly time-of-flight ratio measurements of ${ }^{6} \mathrm{Li}$ glass and fast plastic scintillators, should help.

As to analysis of data, I remember a wise dictum of Eric Lynn in response to a question at Antwerp in 1965. He had spoken on the strong interference effects of fission resonances but advised the experimentalist to continue to use the traditional isolated resonance parameter description, leaving the theoretician to reinterpret the results with more elaborate formalisms. Beyond this one still has use for Occam's razor when describing capture where resonances are unresolved. Prescriptions like $D_{J} \pi=D_{0}(2 J+1), \Gamma_{\gamma}=\bar{\Gamma}_{\gamma}$ independent of $J, \pi, l$, serve to reduce the ambiguity of description. I feel they should continue to be used except where shown to be inadequate.

III. Gamma Detectors for Neutron Capture Cross Sections

As the history of this subject is quite familiar, I confine myself to advantages and limitations of detectors in recent or current use for prompt gamma cascade measurement. These range from the large (2 meter diameter) liquid scintillator tank to small scintillators (such as $\mathrm{NaI}(\mathrm{T} 1) 10.2 \times 12.7 \mathrm{~cm}$ and $\mathrm{C}_{6} \mathrm{~F}_{6} 4 \mathrm{x}$ $10.2 \mathrm{~cm}$ ) and converter-scintillator combinations developed from the original Moxon Rae detector. ${ }^{6)}$

Typical capture gamma cascades give 4.8 to over $10 \mathrm{MeV}$ of total gamma ray energy per neutron captured. While cascades of 4 to 5 gamma rays with average energies of 1-2 MeV are usual, cases where a single gamma ray (near $7 \mathrm{MeV}$ ) is prominent are known and such rarities often lead to added interest in the data. In the large tank detectors most of the volume is needed to raise the efficiency for the rare high energy gamma rays ${ }^{7)}$ but contributes heavily to the background. 
To override background pileup, bias levels of $3 \mathrm{MeV}$ are not uncommon and the necessary extrapolation to zero pulse height is unsupported by observation below $1 \mathrm{MeV}$. As the "spectrum fraction" so estimated is typically 0.5-0.6, it is clear that undetected systematic errors might approach several percent. Half tank coincidence methods to reduce background, in principle re-introduce a strong dependence on cascade multiplicity, though for the important case of ${ }^{238} U(n, \gamma)$ it does not appear significant.

In the small detectors, independence of cascade details is achieved through the method, first put forward by Rae, of making the average detector response proportional to the energy of each gamma ray detected. In the original work 6 ) this was approximately achieved by counting with a thin plastic scintillator the electrons emerging from a gamma converter plate. Material and geometric modifications of this approach to achieve higher efficiency have originated in many laboratories. With such detectors enhanced escape of high energy gamma rays is directly compensated by increased efficiency. At the same time environmental backgrounds are modest and pileup not a problem. The converter plate inevitably absorbs low energy gamma rays so that the lincarity of the cfficiency vs $E_{\gamma}$ relation cannot be maintained below about $0.5 \mathrm{MeV}$. As the abundance of prompt cascade gamma rays below this energy falls rapidly (with few if any below $0.1 \mathrm{MeV}$ or so) their unobservability is of less potential significance than for the large liquid scintillator.

The Moxon-Rae average response characteristic can also be achieved for most detectors by assigning an importance (or "weight") to each event which is a monotonic increasing function of the pulse height. ${ }^{8)}$ This allows considerable freedom in optimizing other characteristics such as sensitivity to sample scattered neutrons, gamma ray stopping power and solid angle.

Swedish laboratories have used this approach with sodium iodide, ${ }^{9)}$ Livermore with a deuterated liquid scintillator ${ }^{10}$ ) and ourselves with fluorocarbon 
liquid scintillators. The sodium iodide provides greater gamma ray stopping power, but somewhat poorer timing capability and a formidable scattered neutron sensitivity through neutron capture in the iodine. This last requires a neutron shield such as ${ }^{6} \mathrm{LiH}$ when a "white" neutron source is used and we have not been successful in trying to measure the angular distribution of capture gamma rays with this detector at ORELA. The fluorocarbon scintillator we use (NE-226) has good timing, fair gamma ray stopping power (density $1.6 \mathrm{gm} / \mathrm{cm}^{3}$ ) and little sensitivity to sample scattered neutrons. Thus no neutron shield is required and pulse heights down to $150 \mathrm{keV}$ can be used. This provides a "spectrum fraction" typically over $99 \%$ for the weighted response (see Fig. 4 of reference 4 ) and of course no sensitivity to the decreased.stopping power for high energy gamma rays. The deuterated liquid scintillator has good timing, somewhat less gamma ray stopping power (density $0.945 \mathrm{gm} / \mathrm{cm}^{3}$ ) and even less probability of neutron capture than for fluorocarbons. Although neutron thermalization and subsequent capture in the surroundings may need to be guarded against, this is probably the detector of choice for neutron capture cross section measurements. With hydrogenous scintillators of modest size, neutron thermalization and capture is generally considered unacceptably large for this application. (In large liquid scintillators the effect is generally suppressed by a few centimeters of ${ }^{6} \mathrm{LiH}$ as a liner and the addition of trimethyl borate ${ }^{11)}$ to compete (via ${ }^{10} B(n, \alpha)$ 's 478 $\mathrm{keV}$ gamma ray) with the $2.2 \mathrm{MeV} \mathrm{H}(\mathrm{n}, \mathrm{Y})$ reaction.

Another consideration in the shape of gamma ray detectors is their sensitivity to non-isotropic angular distributions. This is particularly significant for $\sigma\left(n, n^{\prime}\right) \gamma$ measurements ${ }^{12}$ ) where a single gamma ray is produced for neutron energies between the first and second excited state thresholds. The angular distribution can be described in terms of Legendre Polynomials and is proportional to $\left(1+\mathrm{aP}_{2}(\cos \theta)+\mathrm{bP}_{4}(\cos \theta)\right)$ for quadrupole radiation. The coefficient $\mathrm{b}$ is zero for dipole radiation (and $-1 \leq a \leq 2$ ). The change in total efficiency for 
a number of detector materials and geometries has recently been calculated using an $860 \mathrm{keV}$ gamma ray energy as a test case. In general it is possible to completely cancel the sensitivity to $\mathrm{P}_{2}$ distortion for simple geometries without much sacrifice of efficiency or increase of volume. The sensitivity to $\mathrm{P}_{4}$ distortion was typically small and negative for the geometries studies.

Finally, let me suggest a next-generation capture detector incorporating many of the good features of existing systems. As mentioned above, deuterated liquid scintillator seems the best choice for freedom from scattered neutron sensitivity. The first resonance is near $150 \mathrm{keV}$ in ${ }^{13} \mathrm{C}$ (a $1.1 \%$ isotope in natural carbon) and no more are known below $1.75 \mathrm{MeV}$. There is the possibility of neutron recoil rejection by pulse shape discrimination, as well as good timing down to less than a nanosecond. ${ }^{10}$ ). Much better timing would be of little value in neutron time-of-flight work because of the neutron flight time uncertainty introduced by typical finite target, moderator and sample thicknesses.

A small cylindrical volume provides reasonable efficiency in utilization of the scintillator with ease of fabrication. A central cylindrical duct of $8 \mathrm{~cm}$ or so will accommodate typical samples, including enriched isotopes, as well as a modest ${ }^{6} \mathrm{Li}$ liner if needed. Calculations (see the Figure) show total efficiencies of over $65 \%$ (for $E_{Y}=860 \mathrm{keV}$ ) with cancellation of $\mathrm{P}_{2}$ sensitivity, for volumes of 30 and 64 liters. The importance function for pulse weighting has not been worked out for these cases but is expected to increase somewhat mure steeply than linearly as for the plastic scintillator case (Fig. 4, reference 8 ). While it might be possible following Czirr and Bowman to linearize the weight function using filters, it is probably best to follow the suggestion of R. C. Block to divide the cylinder into a few separate sections to avoid significant coincidence summing. Quadrants would probably be quite sufficient for this and allow placement of a photomultiplier ${ }^{13)}$ at each end of each quadrant. Adding the signals from the two phototubes at the end of a quadrant is a good way to even out the 
light collection efficiency and make the pulse height more uniform as a function of source position. ${ }^{14}$ ) 


\section{REFERENCES}

1. L. W. Weston and J. H. Todd have used similar detectors and pulse height weighting for $n$ measurements.

2. Three years ago we considered concentrating on the $\mathrm{Fe}, \mathrm{Cr}, \mathrm{Ni}$ of your conference. The extensive RPI work on capture in these elements, however, led us to check quickly on the chromium isotopes. Substantial agreement with the RPI resonance structure in this case led us to defer further work on those elements. Recent high resolution transmission data on $\mathrm{Fe}$ showing many $\mathrm{p}$-wave resonances in ${ }^{56} \mathrm{Fe}$ above $100 \mathrm{keV}$ have led to a specific request for capture measurements on them. A suitable enriched sample has been procured for this and data taking is expected in April 173.

3. R. L. Macklin, Nucl. Instr. and Meth. 91, 79(1971).

4. R. L. Macklin and B. J. Allen, Nucl. Instr. and Meth. 91, 565(1971).

5. R. L. Macklin, N. W. Hill, and B. J. Allen, Nucl. Instr. and Meth. $\underline{96}$, $509(1971)$.

6. M. C. Moxon and E. R. Rae in Neutron Time of Flight Methods, J. Spaepen ed. (European Atomic Energy Community, Brussels, 1961).

7. Some $15 \%$ of $7 \mathrm{MeV}$ gamma rays escape from even a very large liquid scintillator (2 meter diameter, $20 \mathrm{~cm}$ central duct) for example.

8. This powerful technique was originally pointed out to me by H. Maier-Leibnitz and is described and applied in R. L. Macklin and J. H. Gibbons, Phys. Rev. $\underline{159}, 1007$ (1967).

9. G. Nystrom, B. Lundberg, and I. Bergqvist, Physica Scripta 4, 95(1971).

10. J. B. Czirr and J. S. Lindsey, Nucl. Sci. \& Eng. 41, 56(1970).

11. J. H. Gibbons, R. L. Macklin, P. D. Miller, and J. H. Neiler, Phys. Rev. $122,182(1961)$.

12. F. G. Perey, W. E. Kinney, and R. L. Macklin, Proc. Third Conf. Neutron Cross Sections and Technology $191(1971)$ ed. R. L. Macklin, USAEC Report CONF-710301.

13. The RCA-4522 Photomultiplier has been used satisfactorily here.

14. E. Haddad et al., Nucl. Instr. and Meth. 31, 125(1964). 


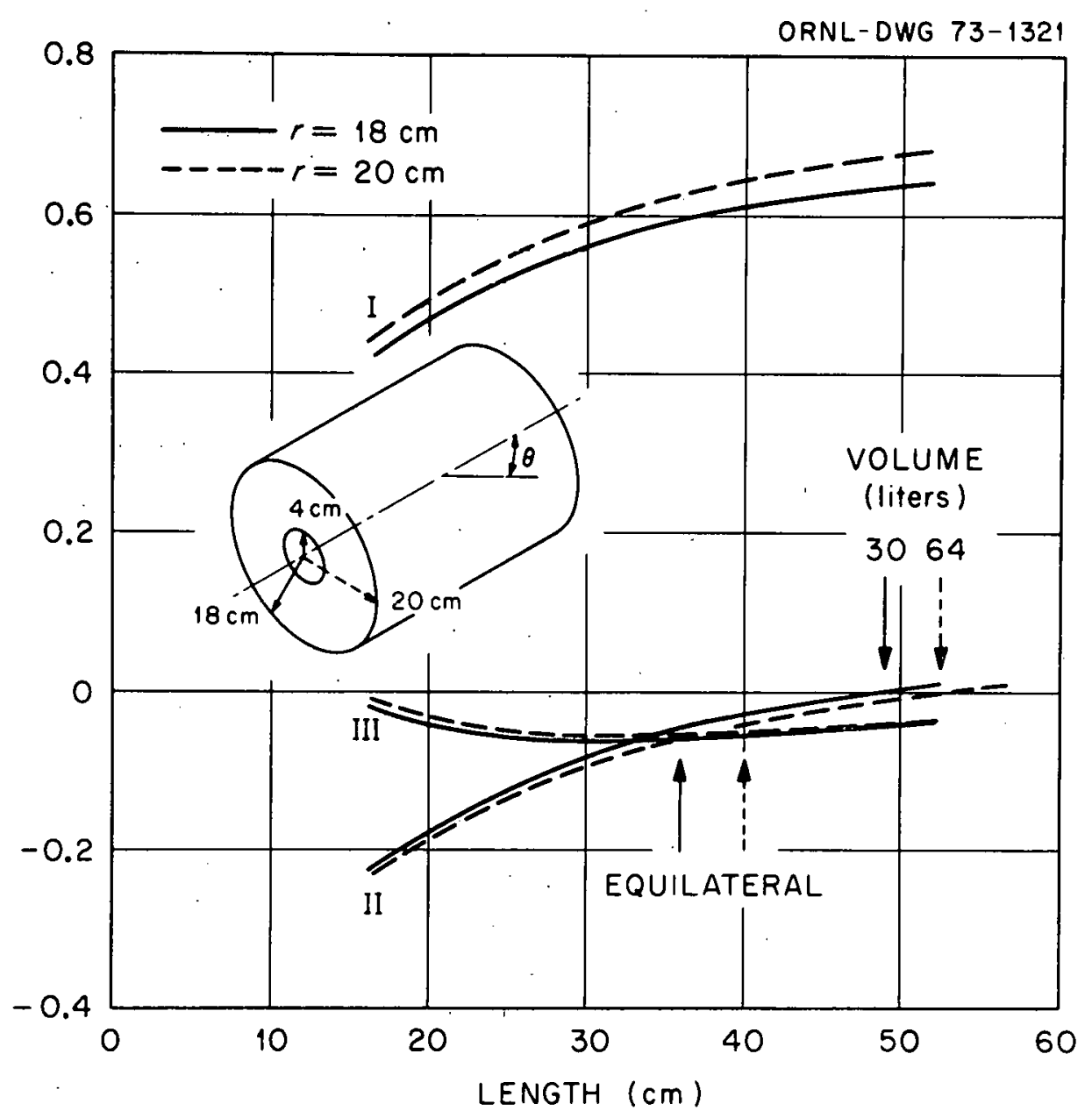

Tntal Ffficiency and distortions for an $860 \mathrm{keV}$ gamma source centered in hollow cylinders of $\mathrm{C}_{6} \mathrm{D}_{6}$.

I. Efficiency for an isotropic source as a function of the length of the detector for two outer detector diameters.

II. Fractional reduction in efficiency for equal $P_{2}(\cos \theta)$ distortion of the source angular distribution (i.e. $1+\mathrm{P}_{2}(\cos \theta)$ distribution).

III. Fractional reduction in efficiency for equal $P_{4}(\cos \theta)$ distortion of the source angular distribution (i.e. $1+\mathrm{P}_{4}^{4}(\cos \theta)$ distribution). 
¿

THIS PAGE

WAS INTENTIONALLY

LEFT BLANK 


\section{DISTRIBUTION}

\section{External}

1. B. J. Allen, Australian Atomic Energy Comnission, Lucas Heights

2. R. C. Block, Rensselaer Polytechnic Institute

3. R. E. Chrien, Brookhaven National Laboratory

4. J. B. Czirr, Lawrence Livermore Laboratory

5. M. P. Fricke, Gulf General Atomic

6. H. E. Jackson, Argonne National Laboratory

7. H. Maier-Leibn1tz, Institut Max von Laue, Grenoble, France

8. M. C. Moxon, Atomic Energy Research Establishment, Harwe11, England

9. G. Nyström, Lund Institute of Technology, Lund, Sweden

10. W. P. Poenitz, Argonne National Laboratory

11. P. Ribon, CEN, Saclay, France

12. G. L. Rogosa, USAEC, Washington, D. C.

13. B. Schatz, Karlsruhe, Germany

14. G. Vanpraet, State University Center of Antwerp, Belgium

15. R. R. Winters, Denison University, Granville, Ohio

\section{Internal}

16. G. T. Chapman

17. G. de Saussure

18. J. L. Fowler

19. W. M. Good

20. J. Halperin

21. J. A. Harvey

22-42. R. L. Macklin

43. F. G. Perey

44. A. M. Weinberg

45. L. W. Weston

46. A. Zucker

47-48. LRD-ORNL

49. ORNL-RC

50-51. Techniral Tnformation Center, $O R$

52-53. Central Research Library

54. Document Reference Section

55. Research and Technical Support Div., OR 